\title{
E-Assessment: Developing Technology Application Prototype for Easy Evaluation of Students' Assignments
}

\author{
Nurul Nisa Omar and Yi Jun Phung
}

\begin{abstract}
This study aims to develop a prototype of an electronic assessment tool to assist lecturers in evaluating students' assignments via technology application platform. This paper documents the process of creating the prototype content and requirements that can easily evaluate students' assignments. The research utilizes qualitative method by analyzing focus group discussions. The findings will be used as the foundation for generating the basic function and concept in the development of an e-assessment application called Operational Metric Assessment and Rubrics (OMAR). This prototype includes features such as an easy-to-use template to generate assignment rubrics, operationalized the metric calculation of students' marks, an automatic generated feedback function and video capture or tapping features in assessing students' presentation. Developing a prototype that can enhance the innovative use of technologies in assessment activity is a great breakthrough in the research world.
\end{abstract}

Index Terms-E-assessments, technology application prototype, innovative assessment technology.

\section{INTRODUCTION}

The development of technology application to support assessment activities not only can further enhance the current practices but it also provides many new possibilities in digitalizing assessment method [1]. The role of technology in education has complimented many assessment practices such as online test, real-time quizzes and technology-based instructional materials [2]. Additionally, past researcher discussed the importance for lecturers to implement digital tools in their teaching and learning activities [3].

Currently, most of the lecturers utilize assessment rubrics in measuring learners' level of performances [4]. However, the metrics calculation for each rubric may differ from one lecturer to another. Additionally, the assessment system can be designed in such a way that satisfies both the technical and content requirement consistently [2]. Thus, by adopting the appropriate technology, lecturers can use more standardized rubric systems for the whole programme.

Due to the huge benefits of an e-assessment, it is vital to understand the lecturers' needs before generating the requirements needed to form the basic content and function on how the e-assessment should operate. Therefore, the objective of this research is to investigate features that can

Manuscript received July 30, 2018; revised December 12, 2018. This work was supported in part by KDU University College under Grant KDURG/2017/1/009.

The authors are with KDU University College, Malaysia (e-mail: nurulnisa.o@kdu.edu.my,0111729@kdu-online.com). enhance the process of assessing students' assignments followed by creating the content and requirements of an e-assessment prototype by adopting these features. To achieve the objective, a case study was done on university lecturers by conducting a focus group discussion in finding out their perspective on the use of technology in assessment activities. The main contribution to developing an innovative assessment technology via e-assessment is to include features to improve the process of evaluating students' assignment.

\section{LITERATURE REVIEW}

Technology has drastically shaped the education field as it has changed the routine and practices of educators [5]. The importance of Information and Communication Technologies (ICT) in education settings as it emphasizes the significance of implementing a digital platform such as internet as a form of communication [6]. Additionally, research has shown that ICT has an important role in the context of teaching, which enhances the students' learning process [7].

There are various ways that technology can assist educators which do not limit to basic teaching activities but also manage classroom environment, involved in administration and conduct assessments. The studies of utilizing technology in the field of assessments are comprehensive in both theory and practice, but not heavily regulated or standardized. Besides which, an assessment is known to be vital in the progression of developing curriculum and teaching process [8]. They expressed the idea of integrating an effective technology with assessment as the goal for educational technology professional development and should be prominent in any evaluation model. The general evaluation model covers grading and giving feedback on assignments in many forms such as in the form of written reports or live presentations. These can be done better with the help of technology.

A restructured technology in assessments or new creation of e-tools are "effective when they are allied to assessment approaches that enhance the students' ability to generate internal feedback against standards and to self-regulate their learning" [1]. The scholars have noted that the current technologies can amplify the current assessment format [8]. Technology-based assessments such as online tests, real-time quizzes and technology-based instructional materials are helpful for both parties; educators and students [2]. Similarly, it was stated that technology should be utilized to address the fundamental educational issues rather than creating more technology platforms just to populate the market [1].

To exclude the use of technology from assessments or any 
type of education tasks will prevent educators from reaching their full potential in today's digital era. Similarly, innovation in formative assessments propels and improves pedagogy [9]. In fact, it is "recommended that education stakeholders should articulate and support a shift in assessment from the dominant high stakes, test-based evaluation model... to a balance of models that more effectively measure the preparedness of today's digital age learner," [6].

However, with the benefits of technology assessments and the support from scholars, the integration is still dependent on educators' digital literacy. Scholars have also noted that the absence of knowledge related to technology serves as an obstacle to the full implementation of technology in the overall teaching process [8]. While there are e-learning platforms and online classes available, the core structure is still an educator-student formation for many institutions. If the educator is digital illiterate, the benefits would not be realized. In a digital era, the "increased integration and adoption of digital technologies in the contexts of both formal and informal learning environments" as well as "teachers' development process in relation to the concept of DL [digital literacy] requires greater attention" [10].

The key components are to use appropriate technology or digital tools to execute many tasks that also include evaluation, assessment and developing media platform for communication. Digital literacy also covers the aspect of technological literacy, informational literacy, communication literacy and multimedia literacy [11]. Without master it, the technological assessments will be pointless since it is a necessary step before introducing such inventions [12].

The author believes that the creation of e-assessment will enhance the innovative use of the technology in education as well as improve educators' productivity. The e-assessment concept can operate a better evaluation model for grading assignments and encourage educators to provide feedback. Thus, it is important to understand what features or functions should be included in the e-assessment platform that can address educators' needs as this will improve their current ways of evaluating assignments.

\section{RESEARCH METHODS}

The following section discusses the research methods and materials used in gathering and processing the data. A case study on university lecturers was done and the method utilizes a qualitative approach by analyzing transcripts of the focus group discussions on the lecturers' view towards using technology platform in assessing students' assignments. The basic content and function of the e-assessment prototype were formed based on the key findings of the discussions.

\section{A. Participants}

The case study was done on lecturers from the School of Communication and Creative Arts in KDU University College, Malaysia. 10 participants took part in the focus group discussion and they are the subject matter experts in communication, language, creative arts and media studies. Convenient sampling was used to select the sample. Data were collected from a population of members who were conveniently available and accessible to the researchers.

\section{B. Focus Group Discussions \& Procedures}

Invitation to participate in the discussion was sent out via email where the objective, venue and details of the discussions were shared. There were 5 participants each for two sessions. The focus group consisted of one moderator and one assistant moderator. Sets of questions were prepared beforehand to guide the flow of the discussion. Participants were asked to discuss their usage of technology at work, usual assessment practice, common feedbacks practice and their needs and request towards implementing a technology-based application for assessment purposes.

\section{Data Analysis}

Audio recordings of the discussions were collected, transcribed and the key themes of the discussion were formed via scissor-and-sort analysis technique. The first step was to identify discussions that were relevant to the objective of the study. Next, different points were coded for any topic but the analysis was done only on subjects that fit the objectives. Once the coding process is complete, several subjects were grouped together to form categorization of themes based on cross-analysis method through the frequency count of the coded subject. There are 127 total codes and 18 subjects with an average frequency of $n=7(127 / 18)$. The subject will only be selected if the frequency count is above $7(n>7)$.

\section{Implementing Data for e-Assessment Prototype}

The generated themes from the analysis were used as a reference in generating the basic requirements needed in forming contents and functions to be adopted into the e-assessment prototype. The prototype was created according to the generated requirements, including features that can ease the evaluation process of students' assignments.

\section{FINDINGS AND DISCUSSIONS}

This section presents the findings from the focus group discussions followed by the development of the e-assessment prototype. The first part provides an overview of lecturers' needs and requests based on their current usage of technology, usual assessment practice and the common feedback practice. The second part documents the adaptation of the important themes generated from the focus group findings into the contents and requirements of the e-assessment prototype.

\section{A. Focus Group Findings}

The focus group findings were categorized into 3 sections: usage of technology, usual assessment practice and common feedback practice. Each category consisted of several themes according to the coded subject with the frequency of $n>7$. The first section covers discussions on the regularity in using technology, the main usage of current technology and the needs and requests in developing new technology platform.

Table I above shows that most participants generally agreed that the current usage of technology was effective. Majority of the lecturers were fairly regular users of technology with an average of 3-4 applications being utilized in one semester to assist their work. However, they were primarily for administrative and class management purposes.

I use a lot of Schoology to distribute assignments or to run quizzes and I find it effective. Typically, it is to share lecture 
notes, assignments, posting announcements or updates, and sometimes interacting with students by conducting discussions. (Participant 05)

TABLE I: USE OF TECHNOLOGY

\begin{tabular}{ll}
\hline \hline Themes & Subject Descriptions (frequency count of $n>7)$ \\
\hline $\begin{array}{l}\text { Regularity in using } \\
\text { technology }\end{array}$ & $\begin{array}{l}\text { Participants are fairly regular users of technology } \\
\text { and they find the usage of it is effective }(n=9) .\end{array}$ \\
\hline $\begin{array}{l}\text { The common use } \\
\text { of technology }\end{array}$ & $\begin{array}{l}\text { Participants' main purpose in using technology at } \\
\text { the workplace is for administrative and class } \\
\text { management tasks such as distributing course } \\
\text { materials to students }(n=11) .\end{array}$ \\
\hline Needs and requests & $\begin{array}{l}\text { To have technology that can help to increase } \\
\text { productivity }(n=8) .\end{array}$ \\
\hline \hline
\end{tabular}

As for their needs and requests for the usage of new technology, they preferred to have something that can minimize the time spent in their work. In this way, this will increase their productivity.

When there are more than 100 students in a class, time is the essence. I don't have enough time and this will affect productivity. So, technology is supposed to help us in reducing the time and increase productivity. (Participant 01)

The second section discussed the participants' usual practice in handling assessments. It covers the usual type of assessments, assessment routine and their technology usage, needs and requests when assessing students' assignments.

TABLE II: USUAL ASSESSMENT PRACTICE

\begin{tabular}{ll}
\hline \hline Themes & Subject Descriptions (frequency count of $n>7)$ \\
\hline $\begin{array}{l}\text { Types of } \\
\text { assessments }\end{array}$ & $\begin{array}{l}\text { Usual submissions of assignments are written } \\
\text { work, presentations and projects }(n=8) .\end{array}$ \\
\hline $\begin{array}{l}\text { Assessment } \\
\text { routine }\end{array}$ & $\begin{array}{l}\text { Typically, the routine in assessing is to print } \\
\text { hardcopy rubrics and give marks accordingly on } \\
\text { papers. Then, lecturers will key in the allocated } \\
\text { marks into the operating system }(n=10) .\end{array}$ \\
\hline Technology for & $\begin{array}{l}\text { Technology in assessment activities is only } \\
\text { practiced when quizzes or exercises are conducted } \\
\text { assessment }\end{array}$ \\
\hline & $\begin{array}{l}\text { Technology that can assist in generating some } \\
\text { standardized rubrics and also easy-to-use }(n=12) . \\
\text { Technology to capture recorded moments of } \\
\text { presentation for easy marking. } \\
\text { Encourage practicing a paperless working } \\
\text { environment }(n=10) .\end{array}$ \\
\hline \hline
\end{tabular}

Table II shows that common types of assignments: written work, presentations and projects. Usual practice would be for lecturers to first prepare the assignment rubrics followed by the evaluation and marking processes that were done on a printed copy of the rubrics. Each semester, the rubrics might be different depending on the learning outcome of each subject and the marking rubrics also differ from one lecturer to another (some grade it over 50 or 100). The lecturers will then key in the marks allocation manually on the operating system. Utilization of technology for assessment only involves quizzes or test that was done online.

When there's a written report submission, for example, there will be a rubric that lists down what is needed to assess the work according to the learning outcome. Then we just print it out and mark manually. (Participant 03)

My marking calculation will be over 100 so it will standardize with the operating system on Oracle. I will make sure my rubrics for every assessment is per 100. (Participant 08)

For me, if the coursework is out of 50, I will set the rubrics calculation to be out of 50, only then I will manually double it up to be out of 100. Something I have rubrics that calculated up to 40 marks, then I will convert it to out of 20 , followed by turning it out of 100. (Participant 09)

Technology use for assessment is only when I do an online test. When there is a lot of students and questions are rather simple like MCQ, short answers, or True or False, I will utilize the online rubrics from Schoology. (Participant 06)

As for the needs and requests for technology-based assessments, it is important to create a system that can standardize the rubrics and also make it user-friendly. Another request is to have a function where students' live presentation can be captured and labeled so lecturers can refer to it and assess later. Lastly, a more advanced request is to run a paperless environment where submissions or assessments do not have to be printed and can evaluate online. The standardized rubrics, video capture presentation and paperless suggestions proposed an easier way to assess students' work and also minimizes multi-tasking and extra work. The usual assessment practice is limiting efficiency and utilization of technology can improve their current practice.

If there is a technology-based assessment, I wish for it to be a standardized rubric or perhaps an application that can search for rubrics that is suitable for the assignment. (Participant 10)

What would be nice is to have an application that can record students' work because when it comes to presentation or performance, it is good to be able to record it and then view it and assess it rather than to mark it while they are presenting. Maybe the technology can help us to formulate the presentation assessment. (Participant 08)

We would like to go paperless and limit our work as much as possible. If we already require doing softcopy, I don't see why we need to do it again for hardcopy. If I do not need to do the paperwork, I will just run everything online but as it is the university requirement, there is nothing much we can do to change that. (Participant 05)

The third section discusses the common feedback practice among participants. This is to find out the usual method for providing feedback to the students and how technology can improve the way students retrieve the feedbacks for their submission.

As shown in Table III, the lecturers' common challenge is in handling a large number of students where individual feedback is difficult. Thus, the usual practice is to identify a general feedback that can serve all students and announce it in the classroom. Ideally, they would like to provide feedback to students individually but it is not practical due to the time limit. To help them, lecturers will pick the common mistake and address it to all students. Other than announcing in the classroom, lecturers also utilize online platform in sharing feedbacks such as creating an online discussion page where everybody can review and write comments. However, lecturers mentioned that students' willingness to participate in the online discussion is relatively poor.

I would like to give feedback to all students individually but because of the large number, I do not have the time to do so. Ideally, it is good to give feedback one by one but it will require a lot of free time which is a luxury that I don't have. 


\section{(Participant 05)}

If I have a lot of students, I will pick on the common mistakes and just tell everyone that these are the common mistakes from the submission and I will remind them not to repeat these mistakes but I will not mention names on whose submissions. If I don't have that many students, I will just talk to them one by one. (Participant 07)

TABLE III: COMMON FEEDBACK PRACTICE

\begin{tabular}{ll}
\hline \hline Themes & Subject Descriptions (frequency count of $n>7)$ \\
\hline General feedback & $\begin{array}{l}\text { Usual feedback practice is to announce in a } \\
\text { classroom the general feedback to all students } \\
\text { because of the big number of students }(n=9) .\end{array}$ \\
\hline \multirow{3}{*}{$\begin{array}{l}\text { Pick common } \\
\text { mistakes }\end{array}$} & $\begin{array}{l}\text { Lecturers will usually take note of the common } \\
\text { mistakes and notice that they tend to write the } \\
\text { same feedback on each submission to address this } \\
\text { common mistake }(n=9) .\end{array}$ \\
\hline \multirow{3}{*}{ Online feedback } & $\begin{array}{l}\text { It is very common for lecturers to provide online } \\
\text { feedback where discussions and comments can be } \\
\text { via Schoology ( } n=11) .\end{array}$ \\
\hline Needs and requests & $\begin{array}{l}\text { Technology that can assist in generating feedback } \\
\text { to avoid writing the same comment on every paper } \\
\text { ( } n=13) .\end{array}$ \\
& $\begin{array}{l}\text { Even though generated feedback is good, but the } \\
\text { lecturer still needs to provide personalized } \\
\text { feedback so that the students will not feel like the } \\
\text { feedback is generated from the computer }(n=8) .\end{array}$ \\
\hline \hline
\end{tabular}

I will just give a general feedback. I will announce it in the classroom what are the common strengths and weaknesses, how everyone can do better and what I expect to see in the next submission. The feedback will be general that every student can learn from it. (Participant 08)

For a large number of students, lecturers find themselves writing the same comments repetitively and when marking process proceeds longer, they end up writing shorter comments. Their request and need would be for technology to create a generated feedback function where it can assist them to avoid writing the same comment. At the same time, they wanted to generate personalized feedback individually because lecturers perceive that students do not want to receive feedback from the computer and they prefer a direct feedback from the lecturer.

When we are handling big classes, we noticed sometimes we write the same comments while assessing their work and our comments become shorter and shorter over time. (Participant 01)

Students will usually want to hear the feedback from me. In what we are doing, we cannot depend too much on technology to provide feedback. As technology is very easy to access and generate feedback, students might discard it. Hence it is good that I personalized the feedback myself. (Participant 08)

\section{B. E-Assessment Prototype Development}

The e-assessment prototype was created for easy evaluation of students' assignment. This section documents the concept, functions and features of the prototype application. The contents and requirements of the e-assessment prototype were generated according to the findings of the focus group discussion.

Table IV shows the content features of the e-assessment prototype that was generated from the focus group findings. There are five main features generated which include standardize and easy to use rubrics, operationalize metric calculation, auto-generated feedback, a video marking capture and recording as well as generate an assessment report.

TABLE IV: GENERATED CONTENTS FOR THE E-ASSESSMENT PROTOTYPE

\begin{tabular}{ll}
\hline \hline Content features & Functions and descriptions \\
\hline $\begin{array}{l}\text { Standardized and } \\
\text { easy-to-use rubrics }\end{array}$ & $\begin{array}{l}\text { The function of this feature is to assist lecturers } \\
\text { for easy drafting an assignment rubrics with a } \\
\text { more standardize metric across the programme. }\end{array}$ \\
\hline $\begin{array}{l}\text { Operationalize } \\
\text { metric calculation }\end{array}$ & $\begin{array}{l}\text { The function of this feature is to operationalize the } \\
\text { metric calculation for grading purposes as set by } \\
\text { the rubrics. }\end{array}$ \\
\hline $\begin{array}{l}\text { Automatically } \\
\text { generated } \\
\text { feedback }\end{array}$ & $\begin{array}{l}\text { The function of this feature is to provide an option } \\
\text { for lecturers to run an auto-generated feedback } \\
\text { that was set follow by the level of performance } \\
\text { from the rubrics with an additional option for }\end{array}$ \\
lecturers to personalize their feedbacks.
\end{tabular}

The functions of these features will ease the evaluation of students' assignment through a systematic mode in generating rubrics, easy grading and calculation of marks, efficient way of generating feedback and assessing presentation and to generate the assessment report for easy keeping and archiving.

\section{Operational Metric Assessment \& Rubrics (O.M.A.R)}

By using the results of the generated contents, an e-assessment prototype called Operational Metric Assessment \& Rubrics (OMAR) was created. The basic concept of this prototype is for the application to operationalize the metric calculation in assessing students' work based on the assigned rubrics.

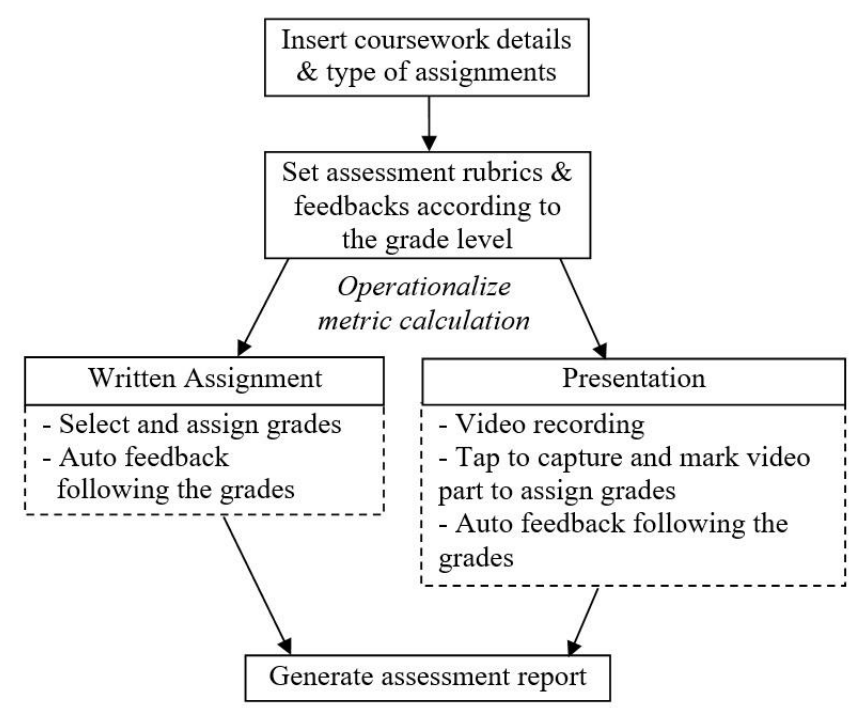

Fig. 1. The flow of the e-assessment prototype.

Fig. 1 shows the flow of the e-assessment prototype. It begins with a page for lecturers to key in the details of the assignments such as types of assessments, weightage, course name and other key information. Next, the lecturers will either use a ready-made rubrics template or assign their own 
rubrics according to the preferred content, metric calculation of the marks and the level of grading as shown in Fig. 2. Each segmented content has specific weightage with the calculation metric.

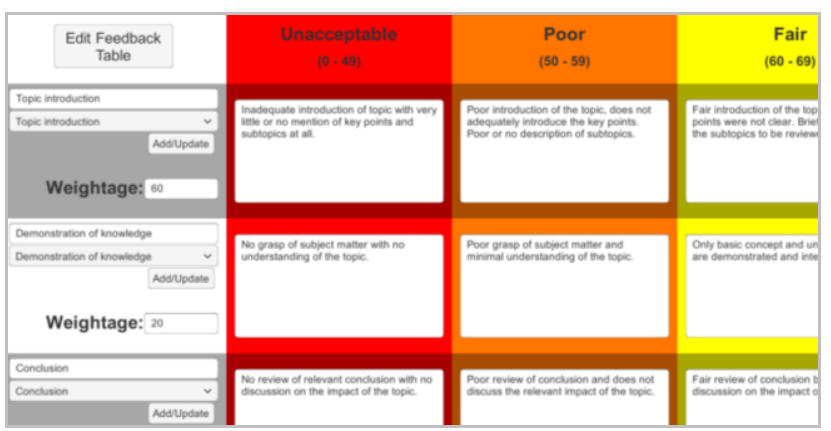

Fig. 2. Standardized and easy-to-use rubrics.

Once the rubric is set, lecturers can use a ready-made feedback template following the grade level or assign their own feedback for each grade segment. The next step is for the lecturers to operationalize the metric calculation of the assigned rubrics to assess students' assignment either in written or presentation format.

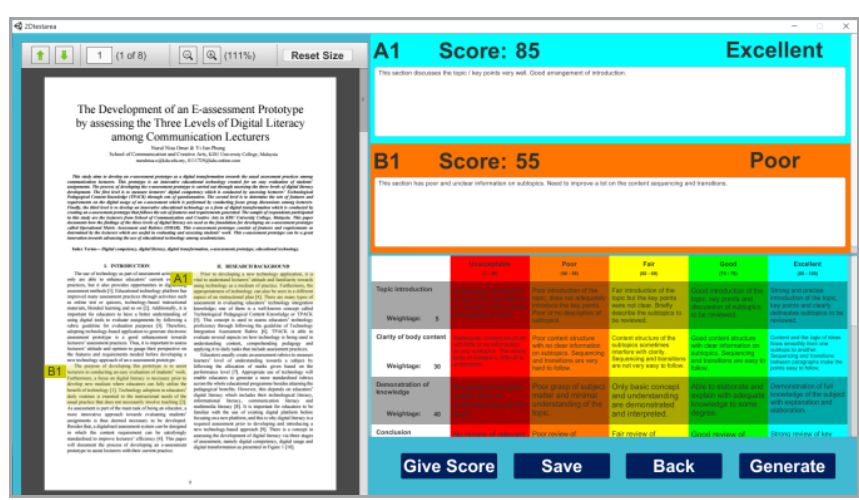

Fig. 3. Operationalize metric calculation.

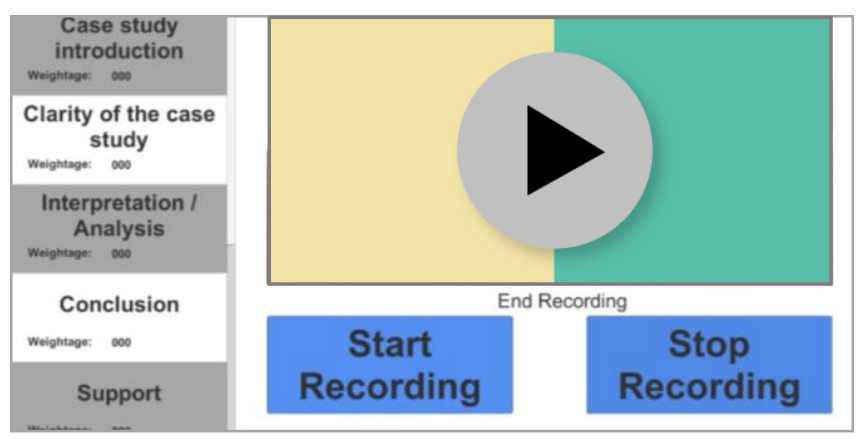

Fig. 4. The video marking capture and recording.

For written assignment as shown in Fig. 3, the prototype allows lecturers to select and assign grades to follow by the pre-set rubrics. For the presentation, as shown in Fig. 4, lecturers are able to record, capture and tap to mark a certain section of the video to assign the grades.

Once the lecturers completed the assessment, they are able to generate the report and save the softcopy version as shown in Fig. 5. The reports will include the feedback, grading for each segment and total marks following the assigned metric calculation. The whole concept of the Operational Metric Assessment and Rubrics (OMAR) prototype were created based on the e-assessment requirements generated from the focus group discussions.

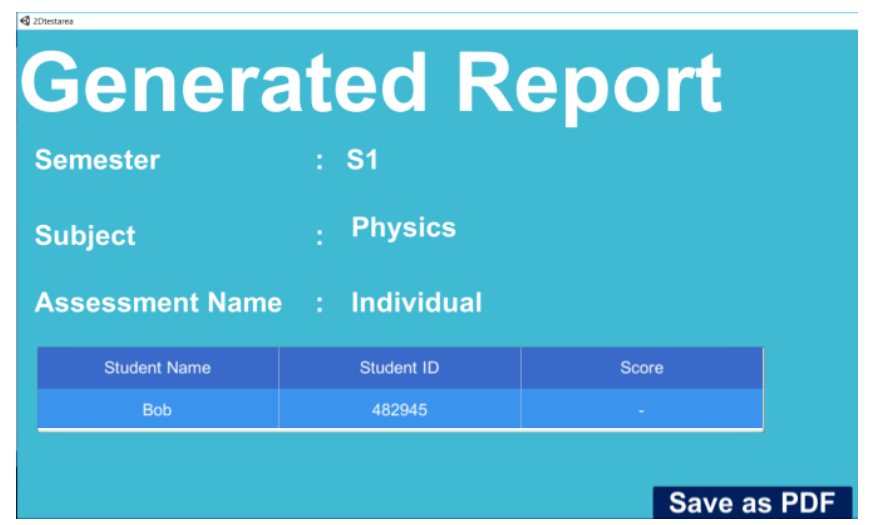

Fig. 5. Generating an assessment report.

TABLE V: REQUIREMENTS TO BE FULFILLED VIA OPERATIONAL METRIC ASSESSMENT AND RUBRICS (OMAR) APPLICATION

\begin{tabular}{|c|c|}
\hline Requirements & Descriptions \\
\hline $\begin{array}{l}\text { Ability to reduce } \\
\text { time in assessing } \\
\text { students' work }\end{array}$ & $\begin{array}{l}\text { The prototype can assist in reducing lecturers' } \\
\text { time by: } \\
\text { 1.Reducing time in grading through the } \\
\text { operational metric calculation features to } \\
\text { run a mathematical calculation. } \\
\text { 2.Providing the option for lecturers to generate } \\
\text { automatic feedback following the level of } \\
\text { performance as set by the rubrics to avoid } \\
\text { writing the same feedback on the } \\
\text { submission. }\end{array}$ \\
\hline $\begin{array}{l}\text { Ability to increase } \\
\text { productivity in } \\
\text { assessment } \\
\text { activities }\end{array}$ & $\begin{array}{l}\text { The prototype can increase lecturers' productivity } \\
\text { by: } \\
\text { 1.Introducing an easier method for grading and } \\
\text { calculation of marks through the } \\
\text { operationalize metric from the rubrics. } \\
\text { 2.Providing a more standardized method of } \\
\text { generating rubrics and assessment } \\
\text { requirements throughout the whole course. } \\
\text { 3.Having an option to add individual comments } \\
\text { even with the presence of auto-generated } \\
\text { feedback to encourage personalizing each } \\
\text { response to the students. }\end{array}$ \\
\hline $\begin{array}{l}\text { Ability to } \\
\text { encourage the } \\
\text { paperless practice }\end{array}$ & $\begin{array}{l}\text { The prototype can encourage the paperless } \\
\text { practice by: } \\
\text { 1. Assessing the assignments fully via the } \\
\text { application instead of printing hardcopy } \\
\text { version of the rubrics as per current practice. } \\
\text { 2.Having students submitting a softcopy version } \\
\text { of the assignment as hardcopy version is no } \\
\text { longer needed. } \\
\text { 3.Having the ability to save and export the full } \\
\text { report of the assessment in pdf for easy } \\
\text { sharing of the report with students. }\end{array}$ \\
\hline
\end{tabular}

Table V shows how the OMAR e-assessment prototype manages to fulfil the requirements generated from the focus group discussion. There are three main requirements: to have the ability to reduce time, increase productivity and encourage the paperless practice. The operationalize metric and auto-generated feedback function will assist in reducing lecturers' time spent on assessing assignments. This follows by increasing their productivity with easier grading method, generating standardize rubrics and a more efficient way of assessing presentation. As for the paperless practice, the prototype allows the assessment to be done via technology and softcopy submission is sufficient.

\section{CONCLUSION}

The use of technology as part of assessment activities has 
been covered in previous researches. Nevertheless, the focus has yet used the concept of operationalizing metric calculation to ease the process of evaluating students' assignment. In this paper, the authors documented the process of creating a prototype that can assist lecturers with their assessment activities. The contents and requirements were generated from the findings of the focus group discussions which were then used as the guideline for creating an e-assessment prototype. From this, a prototype called Operational Metric Assessment and Rubrics (OMAR) was created that consisted of five content features: standardized and easy-to-use rubrics, operationalize metric calculation, auto-generated feedback, a video marking capture and recording, and generated assessment reports. The use of these features contributed to the prototype ability to fulfil the three generated requirements: ability to reduce time in assessing students' work, increase productivity in assessment activities and encourage the paperless practice. Overall, the implication of the results by introducing the features in OMAR prototype application can support and enhance an easy evaluation practice of assessing students' assignments. The limitation of this study is that the generated features are only based on a case study by having focus group discussion only with lecturers from the School of Communication and Creative Arts. For future work, more features can be added by conducting a focus group discussion with lecturers from other fields.

\section{ACKNOWLEDGMENT}

This work was supported by a research grant from KDU University College (KDURG/2017/1/008).

\section{REFERENCES}

[1] D. J. Nicol and D. Macfarlane-Dick, "Formative assessment and self-regulated learning: A model and seven principles of good feedback practice," Studies in Higher Education.
[2] C. Moersch, "Levels of technology implementation (LoTi): A framework for measuring classroom technology use," Learning and Leading with Technology, vol. 23, pp. 40-40, 1995.

[3] M. Shahadat, "Aalborg Universitet A systematic review and development of digital literacy meta-analysis of teachers," 2015.

[4] S. Hamid et al., "An empirical study of lecturers' appropriation of social technologies for higher education," vol. 30, no. 3, pp. 295-311, 2014.

[5] P. Mishra and M. J. Koehler, "Technological pedagogical content knowledge: A framework for teacher knowledge," Teachers College Record, vol. 108, no. 6, p. 1017, 2006.

[6] M. Webb et al., "Challenges for information technology supporting educational assessment," Journal of Computer Assisted Learning, vol. 29, no. 5, pp. 451-462, 2013.

[7] S. C. Kong et al., "A review of e-Learning policy in school education in Singapore, Hong Kong, Taiwan, and Beijing: implications to future policy planning," Journal of Computers in Education, vol. 1, no. 2-3, pp. 187-212, 2014.

[8] B. R. Belland, "Using the theory of habitus to move beyond the study of barriers to technology integration," Computers \& Education, vol. 52, no. 2, pp. 353-364, 2009.

[9] P. Black et al., Assessment for Learning: Putting it Into Practice, McGraw-Hill Education (UK), 2003.

[10] M. S. Khalid et al., "A systematic review and meta-analysis of teachers' development of digital literacy," in Proc. the 1th D4| learning International Conference Innovations in Digital Learning for Inclusion (d4learning, 2015), 2015.

[11] M. Guitert et al., "Digital competence training proposals in the UOC context : A transforming vision," 2010.

[12] E. E. Gallardo-echenique and L. Marqués-molias, Digital Competence in the Knowledge Society, vol. 11, no. 1, pp. 1-16, 2015.

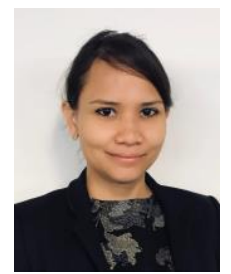

Nurul Nisa Omar is a Ph.D. holder from Multimedia University Malaysia who possesses a passion for teaching and is a dedicated educator. She is very active in research activities and currently leading a research project under a local grant. Her first research achievement was for a paper on educational online games which she achieved the silver award at the International Conference on Advances in Computer Entertainment Technology. She was also awarded Best Ph.D. Thesis Award in Multimedia from Multimedia University, Malaysia. Additionally, she has published several articles in the international journals and she has presented her papers in international research conferences which include Asian Conference on Arts and Humanities, European Conference on Media and Mass Communication, International Conference on Education and Management Technology and many others. 